UDK 783.6 .034

Jože Sivec

Ljubljana
"ECCE, QUOMODO MORITUR JUSTUS" J. GALLUSA IN NEKATERIH NJEGOVIH SODOBNIKOV

(STILNOKRITIČNA PRIMERJAVA)

Primerjava kompozicij, ki so jih zložili na isti tekst različni avtorji, je lahko koristna, še zlasti tedaj, ko gre za dela istega obdobja. Prav ob tem se morejo pokazati v značilni luči določeni vplivi, stilne zveze in razlike. V tej smeri se odpirajo nove perspektive tudi za nadaljnje osvetljevanje ustvarjalnosti Jacoba Gallusa Carniolusa, enega od vodilnih skladateljev renesančne qlasbe druqe polovice 16. stoletja. Tu prihaja za stilno analitično raziskovanje v prvi vrsti v poštev mojstrova monumentalna zbirka motetov "Opus musicum". Ker ta temelji na številnih latinskih tekstih, $k i$ so se stalno uporabljali po posameznih obdobjih liturgičnega leta pri bogoslužju, je gotovo, da so mnoge tekste komponirali še drugi skladatelji tistega časa. Kakor je doslej znano, je 58 besedil, ki jih vsebuje "Opus musicum", uglasbil tudi Palestrina.1

$\checkmark$ naznačeni zvezi se mi zdi zanimivo vprašanje primerjave Gallusovega moteta "Ecce, quomodo moritur justus" z motet istega naslova nekaterih njegovih pomembnih sodobnikov kot so Marc' Antonio Ingegneri, Ludovico Viadana, Orlando di Lasso, Tomás Luis de Victoria in Carlo Gesualdo da Venosa. Iz obsežne tvornosti našega mojstra sem izbral prav to delo, ker je "Ecce, quomodo moritur justus", ki je izšl leta $1587 \mathrm{v}$ Pragiv drugem zvezku zbirke "Opus musicum", že stoletja v glasbenem svetu njegovo najbolj znano delo in sodi hkrati tudi med njegove najbolj popolne stvaritve.2 ob njem hočem upoštevati še nekaj istoimenskih kompozicij, ki so nastale v neposredni ali vsaj relativni časovni bližini. Da se pri tem oziram najprej na "Ecce, quomodo moritur justus" Ingegnerija in Viadane, je razumljivo, ker obstajajo med njunima uglasbitvama in Gallusovo določene skupnosti, očitne že takoj, ne da bi se spustili v podrobnejšo analizo. Za vse je značilna kompaktna homofonska struktura, njihova moč pa je prvenstveno v zvočnosti, akordiki, medtem ko je silabična in deklamativna melodika večinoma podrejenega pomena in izhaja iz harmonije. Kompozicijski

1 Jo Bole, Stilna primerjava nekaterih motetov, ki sta jih Gallus in. Palestrina komponirala na ista besedila, dipl. delo, tipkopis, Ljubljana 1967, 5-7.

2 D. Cvetko, Jacobus Gallus Camiolus, Ljubljana 1965, 137-138, 165, 201; 
stavek členijo pavze, ki nastopajo v vseh glasovih hkrati in tako ustvarjajo kot zareze kratke miselne in oblikovne enote. Razen tega opażamo sorodno osnovno razporeditev muzikalne materije. Povsod gre za isto zasnovo z refrenom ( $A B C B)$, ki pa je že podana v gregorijanskem rasponsoriju.

Od nazadnje omenjenih motetov zbudi pozornost predvsem Ingegnerijev, objavljen leta 1588 v Benetkah $v$ avtorjevi zbirki "Responsoria Hebdomadae Sanctae, Benedictus, et Improperia quatour v. et Miserere sex. v.", saj kaže presenetijivo podobnost $z$ znamenito Gallusovo istoimensko skladbo.3 Posebno močan vtis sličnosti se nam zbudi ob poslušanju njunih začetkov. Tako Gallus kot Ingegneri sta komponirala besede "Ecce, quomodo moritur justus" v okviru muzikalnega stavka, ki obsega 6 taktov (Pr. 1/a, b). Obakrat izstopa uvodni klic "Ecce" od nadaljevanja z uporabo daljših notnih vrednosti in oddelitvijo po pavzi. Tudi harmonska zveza je pri tem analogna. Ceprav je Gallusov motet $v$ jonski tonaliteti in Ingegnerijev v eolski, gre vsakikrat za zvezo T-D in kvartni postop basa navzdol. Se posebno važno je to, da sta si melodiji $\checkmark$ okviru teh 6 taktov zelo podobni, le da je pri Ingegneriju na začetku g zvišan kot subsemitonium modi $v$ gis, medtem ko je na koncu stavka še dodan fis. Melodično in harmonsko je ta kadenca povsem identična s kadenco tretjega stavka pri Gallusu (Pr. $2 / a)$. Končno naj še opozorim, da so akordi sredi stavka v obeh motetih isti: F-dur, B-dur, F-dur ( $v$ notnem primeru so označeni z ležečim oglatim oklepajem). Navzlic navedenim podobnostim pa se seveda pokaže pri analizi vrsta razlik. Gallusov začetek zveni za naše občutje že povsem moderno: $T$ D T S T T Tp6 D $\frac{6}{4}$ DD D,

\section{Primer 1 \\ Gallus}
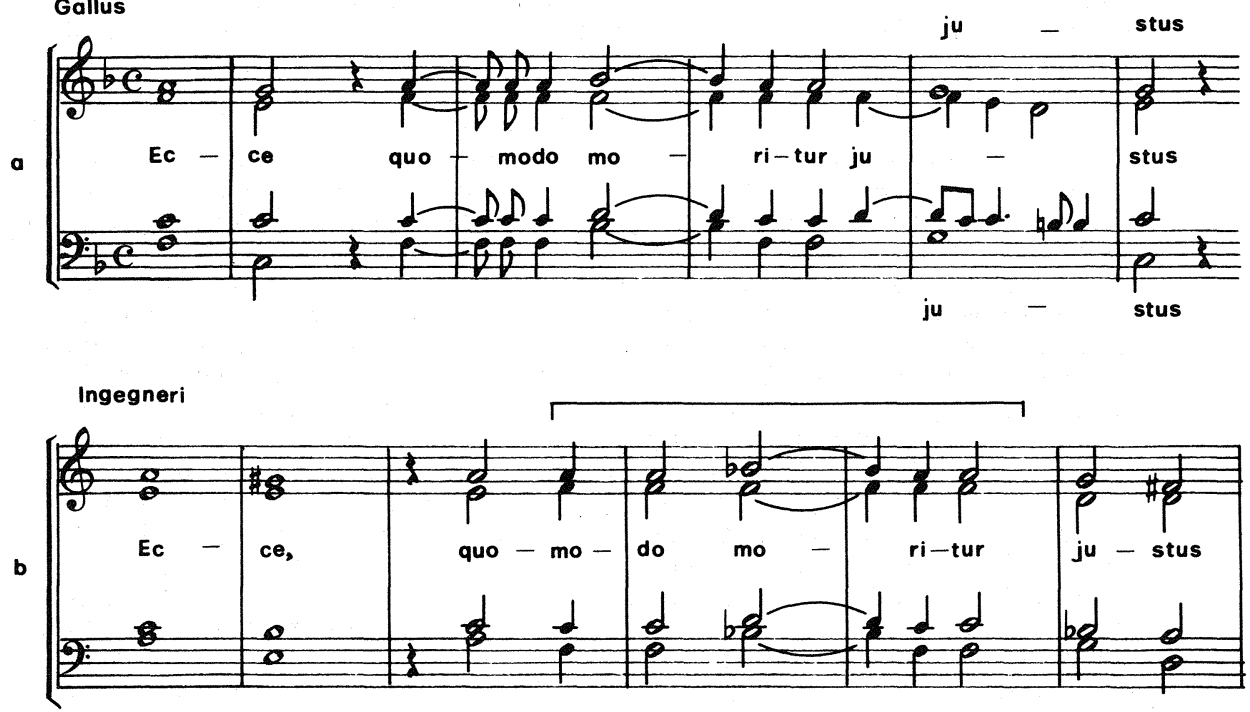

isti, Jacobus Gallus, sein Leben und Werk, München 1972, 81, 82; isti, Musikgeschichte der Südslawen, Kassel-Maribor 1975, 65-66; L. M.

Skerjanc, Kompozicijska tehnika Jakoba Petelina-Gallusa, Ljubljana 1963, 256-258; G. Reese, Music in the Renaissance, New York 1954, 738;

H. Leichtentritt, Geschichte der Motette, Leipzig 1908, 291. 
torej je harmonizacija povsem $v$ skladu s principi poznejse funkcionalne harmonije. Gallusova harmonizacija je preprostejša, trša in svetlejša, saj uporablja skladatelj z izjemo Tp same durove trizvoke. Zaradi kromatike in prevladovanja molovih trizvokov pa zveni Ingegnerijev harmonski stavek nekoliko barviteje in mehkeje. Zato občutimo ta pasus kljub omenjeni identičnosti akordov tudi kot otožnejši in temnejši. V zvezis tem drugačnim izrazom so morda še določeni razločki v ritmu oziroma trajanju notnih vrednosti. Uvodni vzklik "Ecce" se zdi pri Gallusu odločnejši, izzveni bolj odrezano, ker je drugi zlog za polovico krajši od prvega. Pa tudi sicer je pri njem deklamacija zaradi punktiranega ritma pri "quomodo" ostrejša. Besede "et nemo percipit corde" je Ingegneri uglasbil le v enem samem kratkem stavku treh taktov, medtem ko jih je Gallus oblikoval širše, in to $v$ dveh stavkih po tri takte (Pr. 2/a,b).

\section{Primer 2}

Gallus

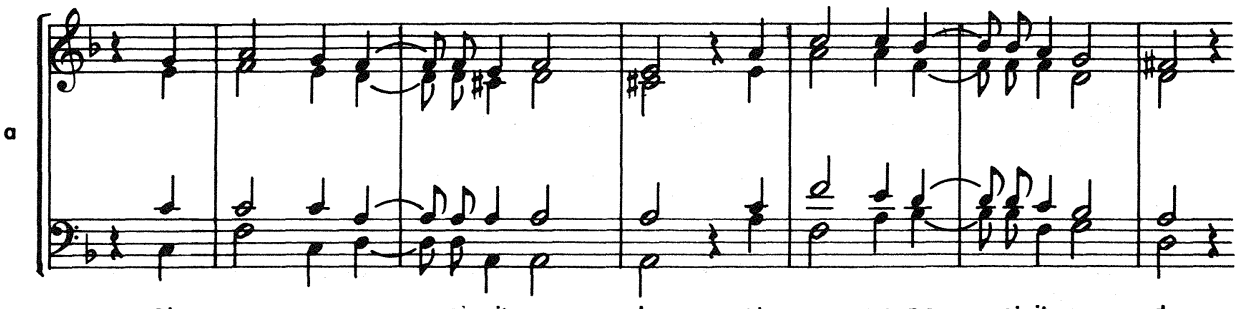

et ne - mo per - ci-pit cor - de, et ne-mo per - cipit cor. - de:

Ingegner

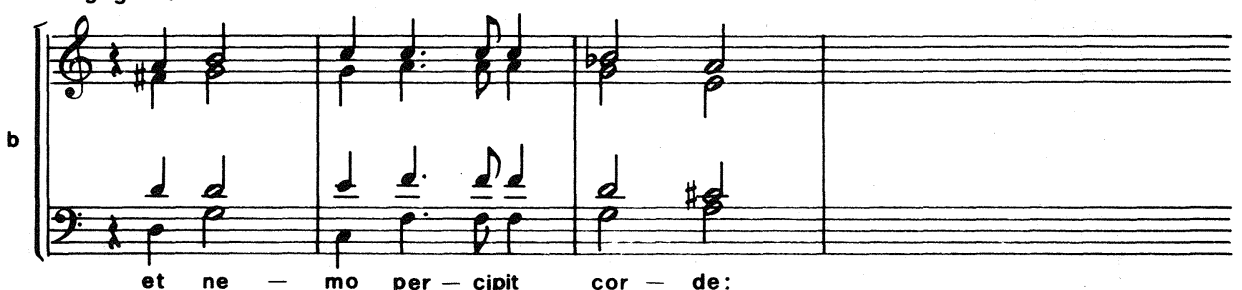

Vsekakor je Gallus dosegel učinkovit zvočni kontrast s tem, da je isti tekst ponovil z novo uglasbitvijo, ki jo je pomaknil $v$ višji glasovni register. Ne glede na navedeno razliko teh pasusov pa je treba ugotoviti enake notne vrednosti $v$ enem kot drugem motetu kakor tudi rahle sličnosti $v$ melodični konturi soprana (gl. pri Gallusu drugi cit. stavek).

Kot Gallus je tudi Ingegneri muzikalno obdelal "viri justi tolluntur, et nemo considerat" v dveh stavkih po tri takte $z$ vmesno četrtinsko pavzo, ki se točno ujema s sintaktičnimi zarezami $v$ tekstu $(\operatorname{Pr} .3 / a, b)$. Medtem ko so notne vrednosti prvega stavka Gallusove in Ingegnerijeve uglasbitve spet iste,

3 Ingegnerija uvršča glasbena zgodovina med pomembne severnoitalijanske komponiste zadnje tretjine 16. stoletja. Deloval je v Veroni in Cremoni, kjer je bil tudi učitelj Monteverdija. Med njegovimi duhovnimi deli je znanih predvsem 29 responsorijev. za veliki teden, ki so dolgo časa 

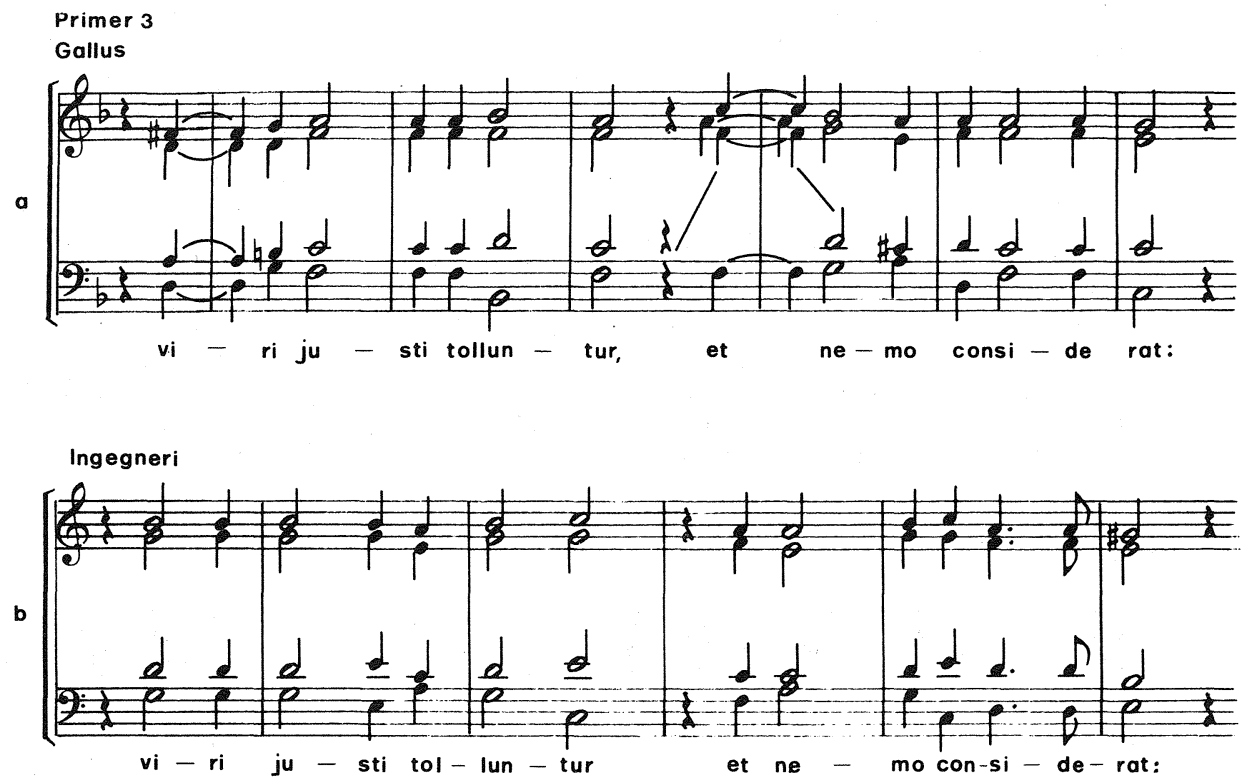

pa se pasusa "et nemo considerat" melodično in harmonsko razhajata.

$\checkmark$ nadaljevanju se začenjata moteta po svojem osnovnem konceptu drug od drugega vse bolj oddaljevati. Stavek "a facie iniquitatis sublatus est justus" je Gallus členil razločno v dve muzikalni enoti (Pr. 4), ki ju loči pavza in markantna kadenca (durov trizvok VI. stopnje s predhodno stransko dominanto).

\section{Primer 4}

Gallus

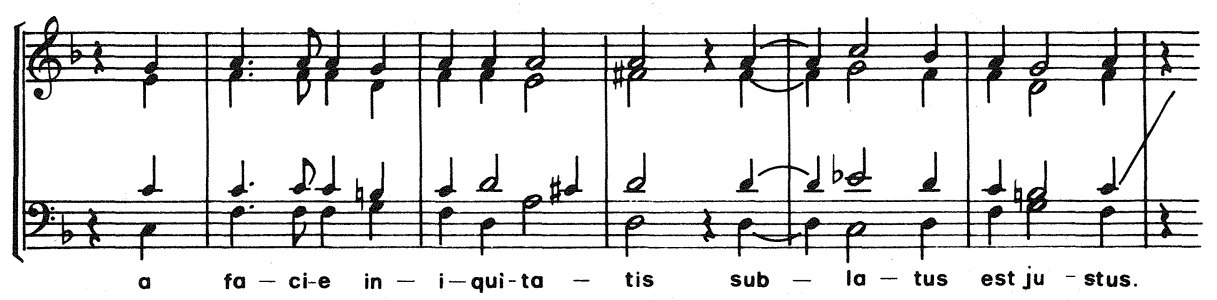

Zaključek druge zveni šibkejše, je na lahko dobo in harmonsko manj izrazit (zveza durovega trizvoka II. stopnje in tonike) ter tako nujno zahteva nadaljnji razvoj skladbe. Nasprotno je Ingegneri komponiral ta odsek (Pr. 5) venem, brez predaha in zveze Tp-Sp v sredini ni občutiti kot kadence. Pač pa je dal Ingegneri močan poudarek zaključku tega šesttaktnega stavka z

veljali za Palestrinino stvaritev. Š F. X. Haberl jih je vključil $v 32$. zvezek celotnih Palestrininih del, čeprav pod oznako "opus dubium". Ravno Haberl pa je pozneje odkril originalni tisk responsorijev in spoznal, da je njih avtor Ingegneri. Kot je nadalje dokazal R. Casimiri, 
Primer 5

Ingegneri

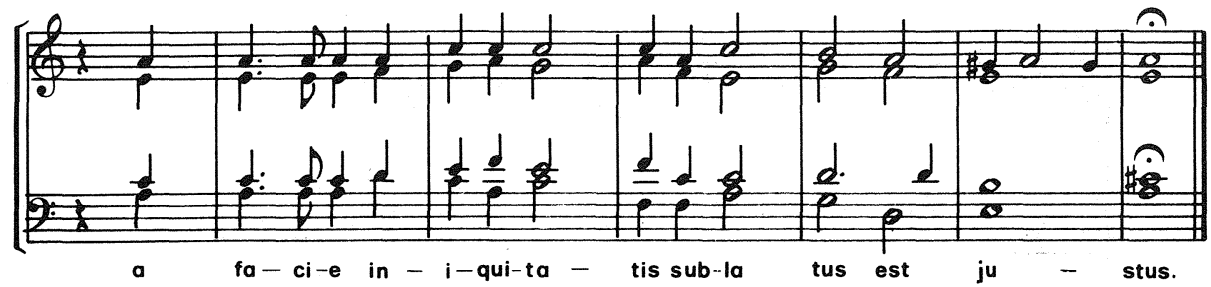

avtentično kadenco D-T. Ta sklep je tako krepak, da se $z d i$, da bi skladba lahko končala že kar na tem mestu.

Tako je refren B "Et erit in pace memoria eius" pri Gallusu (Pr. 6) logično nadaljevanje prejšnjega (a), nekaj, kar se s tem organsko spaja v višjo enoto (I. Pars), dočim občutimo refren pri Ingegneriju kot naknadni dodatek, ki stoji na tem

Primer 6

Gallus

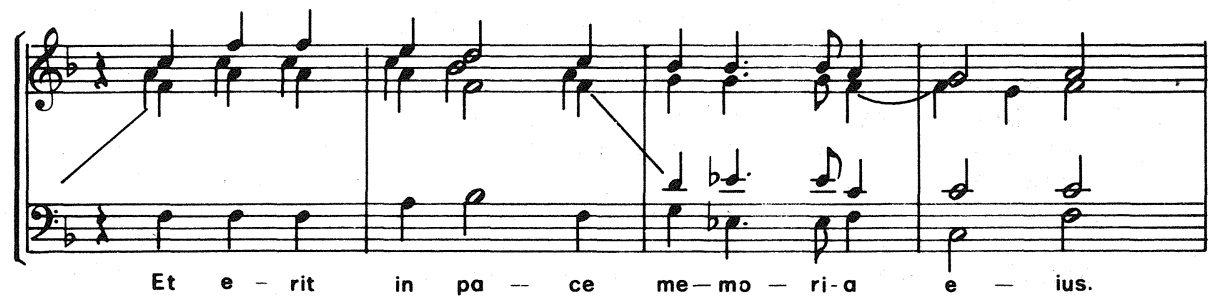

mestu skoro brez nujne zveze s predhodnim. "Et erit in pace memoria eius" je nedvomno ekspresivni višek Gallusove skladbe. Tu se melodija soprana široko razpne v značilnem krepkem postopu kvarte navzgor $\left(c^{2}-f^{2}\right)$, nakar se polagoma spušča po tonih jonske lestvice vse do druge stopnje navzdol. Razen tega ima ta pasus tudi harmonsko nenavadno moč, ki je dosežena predvsem s smotrno uporabo dvojne subdominante. Res redek primer $v$ glasbeni literaturi, da je zgoščeno toliko izraza v melodiji in harmoniji pičlih štirih taktov. Zato se zdi toliko bolj upravičeno, da jih je Gallus že takoj ponovil in s tem še stopnjeval moč zaključka prvega dela in tudi sklepa celotne kompozicije.

$\checkmark$ primerjavi z Gallusovim je Ingegnerijev retiren (Pr. 7) izrazno šibkejši in ne prinaša glede na prejšnji del (a) niti zvočnega niti melodičnega kontrasta. Kot poprej je tu melodija ozko stisnjena, razen tega pa tudi akordi ne učinkujejo močneje. Značilno je, da refren ne izzveni na toniki, ampak neodločno brez harmonske modulacije na dominanti, kar daje vtis v zraku lebdečega sklepa, $k i$ je za naše občutje tuj, a za tedanji čas ni tako neobičajen.

izključujejo posameani kromatiěni postopi avtorstvo Palestrine, ker rimska šola ne pozna kromatike. Prim. MGG, VI, 1213-1215; H.

Leichtentritt, ib., 191; G. Reese, ib., 491; 0. Urspming, Die katholische Kirchenmusik, Potsdam 1931, 188; R. Casimiri, M. A. Ingegneri, Note 


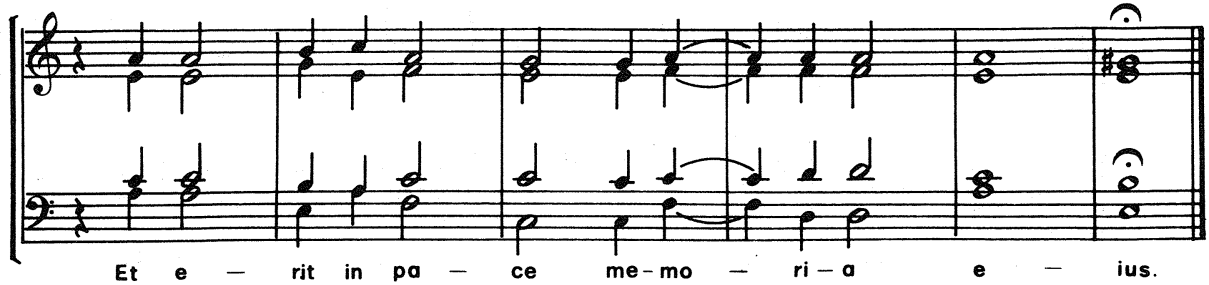

Kljub temu, da je torej po osnovnem muzikalnem konceptu stavek "a facie iniquitatus sublatus est justus" pri obeh skladateljih že tako različen, pa je vendar zanimivo, da sta si melodiji soprana na besede "sublatus est justus" ene kot druge uglasbitve kar precej podobni. Razlika se pokaže le v obravnavi besede "justus". Ce ji je dal Gallus poudarek že takoj na začetku, z uporabo melizma $v$ altu in tenorju (gl. pr. 1/a, takt 4-5), je to storil Ingegneri šle zdaj, ko je odel njen prvi zlog vkrajši melizem (a-gis-a, gis kot subsemitonium modi), ki ga je dodelil sopranu.

Ceprav je doslej obema skladbama skupen tip melodike, ni težko opaziti, da je mestoma Gallusova melodična linija izrazitejša, spevnejša in se odvija v širšem loku. To velja še posebno za refren "et erit in pace memoria", pa tudi za pasus "et nemo percipjt corde". Tu napravi melodija na začetku prve fraze korak gla 1 , od koder gre postopoma na kvarto navzdol, medtem ko se začenja druga fraza za kvarto više (a1) z vzponom na $c^{2}$, nakar sledi postopno spuščanje do fis 1 . Tako je v območju tega pasusa skrajni razmak melodije mala seksta, medtem ko je $v$ refrenu kar mala septima.

ce obstaja v oblikovanju vse do zakijučka refrena vrsta bolj ali manj zaznavnih skupnosti, pa se skladbi zatem povsem razideta. Temu je vsaj deloma vzrok uporaba različnega besedila. Za komponiranje naslednjega c-dela je Ingegneri vzel enako kot pač drugi tedanji skladatelji responsoriju pripadajoć psalmov verz "Tamquam agnus coram tondente se obmutuit et non aperuit os suum: de angustia et de judicio sublatus est", medtem ko ga je Gallus, ki sploh ni uglasbil kompletnega cikla responsorijev za veliko soboto, nadomestil s krajšim besedilom, izhajajočim iz 2. antifone 3 . nocturna iste matutine. ("In pace factus est locus eius, et in sion habitatio eius"). Zato je tudi razumljivo, da je Ingegneri ta del izpeljal muzikalno obsežnejše. Po strukturi kot tematiki predstavlja močan kontrast (Pr. 8). Grajen je preimitirano in je namenjen le trem visokim glasovom (I. in II. sopran in alt). V skladu s takšno zasnovo so zdaj prepletajoče se melodične linije izrazitejše, razvijajo se v širših intervalih in imajo večji ambitus. Tako učinkuje c tudi lahkotnejše nasproti prejšnji kompaktnosti glasbenega stavka. Za razliko od Ingegnerija in nekaterih obravnavanih skladateljev pa je grajen ta del pri Gallusu enako kot ostala kompozicija: je ostro členjen in akordski, a melodija je deklamativnega značaja.

d' Archivio III/1, Roma 1926. 

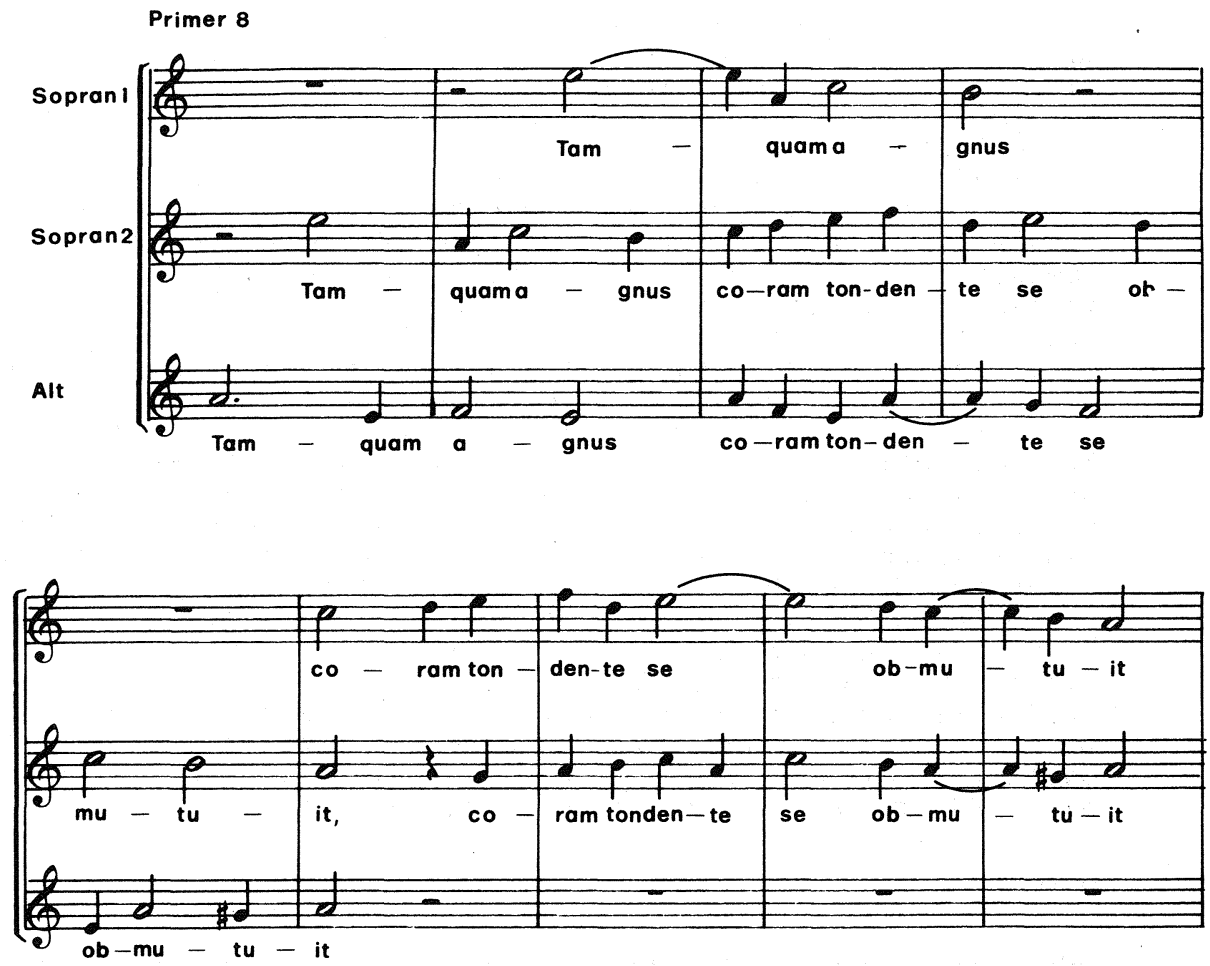

Ob tej primerjavi se nam vsekakor zastavlja vprašanje, od kod omenjene podobnosti med eno in drugo skladbo. Res je sicer, da je Gallusov "Ecce, quomodo moritur justus" izšel leto prej kot Ingegnerijev. Vendar je ta časovni presledek premajhen, da bi bilo verjetno, da je Ingegneri spoznal znamenito Gallusovo skladbo v tisku drugega zvezka zbirke "Opus musicum", predno je morda začel komponirati svoj motet. Seveda je tudi možno, da je Ingegnerijev "Ecce, quomodo moritur justus" celo nekoliko starejši kot Gallusov, saj nikakor ni nujno, da je delo, ki je izšlo pozneje, mlajše. Doslej ni znano leto nastanka ne Gallusovega in ne Ingegnerijevega moteta, pa tudi njune stilne značilnosti ne dajejo nikakršne podlage za ugotavijanje njune morebitne majhne starostne razlike. Vse kaže, da sta skladatelja komponirala isti tekst $v$ neposredni časovni bližini ali morda celo istočasno drug od drugega neodvisno in tako ne moremo govoritio vplivu niti veni niti v drugi smeri. Bila sta pac sodobnika, $k i$ sta se stilno v določenem smislu stikala. Kot sem že omenil, je Ingegneri deloval nedaleč od Benetk, medtem ko je imela odločujoč vpliv na oblikovanje Gallusove skladateljske fiziognomije prav italijanska renesansa, in to še posebno beneška smer. Vsekakor pa izhaja največ sorodnosti med obema kompozicijama iz dejstva, da sta se skladatelja odločila za enak osnovni način uglasbitve istega teksta, namreč za preprosto akordiko in deklamativnost, kar je skoro nujno 
moralo diktirati podobno razporeditev glasbene materije in oblikovno členitev ter sorodno melodično zasnovo. Koincidence, kot jih kažeta začetek Ingegnerijeve in Gallusove skladbe, lahko najdemo $\vee$ glasbeni literaturi tudi v primerih, ko ne obstaja možnost določenega posnemanja.

Mlajši Gallusov sodobnik Ludovico Viadana, znan predvsem $\checkmark$ zveziz začetki zgodnjega baročnega cerkvenega koncerta, je sledil v svoji štiriglasni zbirki "Responsoria ad lamentationes Hieremiae prophetae" (Benetke 1609), iz katere izhaja tudi motet "Ecce quomodo moritur justus"4, še vokalni tradiciji 16. stoletja in tako tu, ustrezno liturgičnemu predpisu za veliko soboto, ni uporabil continua. Njegov vseskozi homofonski in homoritmični "Ecce, quomodo moritur justus", ki ima psalmov verz oblikovan kar kot zborovski recitativs kratkimi melodičnimi obrati ob koncu vsakega polverza, je preprosta kompozicija in ne dosega Ingegnerijeve. čeprav je tu stopnja sorodnosti med Gallusom in Viadano vsekakor manjša kot med Gallusom in Ingegnerijem, pa lahko najdemo med prvima dvema poleg že omenjenih splošnih skupnosti še nekaj sličnosti v posameznostih. Tudi pri Viadani, ki je sicer uglasbitev besed "Ecce, quomodo moritur justus" strnil v tri takte, se uvodni vzklik, harmoniziran spet kot zveza T-D, po daljših notnih vrednostih dokaj zaznavno loči od nadaljevanja, seveda pa je manj izstopajoč, ker je po trajanju realiziran namesto z dvema celinkama (brevis) z dvema polovinkama (semibrevis) in mu ne sledi premor (Pr.9). Razen tega se Viadanin začetek $v$

\section{Primer 9}

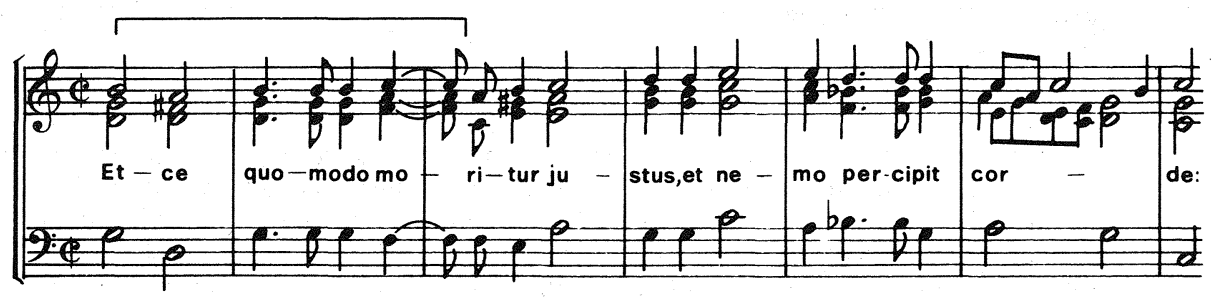

sopranu ( $v$ notnem primeru označen z ležečim oglatim oklepajem) ujema $z$ Gallusovim in kot naš mojster je Viadana zaostril deklamacijo na besedo "quomodo" z uporabo punktiranega ritma. Končno še dodajmo, da je tudi Viadana v obravnavanem odseku z eno samo izjemo uporabil le durove trizvoke. Sicer pa odkrijemo v nadaljevanju Viadanine kompozicije samo še nekaj ritmičnih identičnosti z Gallusovo, tako punktiran ritem na besedah "percipit" in "faciem", ki pa ga na teh mestih najdemo tudi pri Ingegneriju.

Od pravkar obravnavanih motetov se po svojem značaju in gradnji močno razlikujejo "Ecce, quomodo moritur justus" Orlanda di Lassa, Tomása Luisa de Victoria in Carla Gesualda da Venosa. Lassov "Ecce, quomodo moritur justus" je bil napisan v obdobju velike ustvarjalne intenzitete nizozemskega mojstra, ki je trajala od leta 1580 do 1585. Tedaj je nastala poleg

$4 \quad$ Le-ta doslej še ni bil izdan $v$ sodobni ediciji in sem ga za pričujočo študijo spartiral po posameznih glasovih, ki jih hrani Centralna škofijska knjižnica (Bischöfliche Zentralbibliothek) v Regensburgu. 
nenatisnjenega himnarija in pasijonov še vrsta njegovih del za interno uporabo bavarske dvorne kapele, ki jih bržkone ni nameraval objaviti. čeprav nenatisnjene, kompozicije verjetno ne dosegajo višine znanih motetov, ki so bili zasnovani v tistem času, nikakor ne gre za rutinske produkte, ampak za dela, ki se očitno razlikujejo od povprečnega stila münchenske kantorije.5 Starejši Gallusov sodobnik je vzel za svoj "Ecce, quomodo moritur justus" le prvi del teksta responsorija istega naslova. Zato je razumljivo, da je njegova kompozicija znatno krajša. Kolikor je mogoče ugotoviti na podlagi zbirke liturgičnih napevov "Liber usualis", tudi Lasso svoje kompozicije ni gradil na koralnem cantusu firmusu. 6 če je pri Gallusu, Ingegneriju in Viadani težišč na akordiki, stopa pri Lassu v ospredje melodija oziroma linija posameznih glasov. Kljub pretežno polifonski strukturi pa zveni glasbeni stavek še vedno dovolj polno in masivno, kar je skladatelj dosegel z uporabo popolnih trizvokov, ki nastopajo v osnovni legi. Lassov "Ecce, quomodo moritur justus" je oblikovan kot ena sama večja celota, pri čemer ni členjenje zdaleč tako pogosto in razločno. Vseeno pa je glede na kadenciranje in pavze mogoče skladbo smiselno razčleniti v tri stavke.

Nedvomno je izrazita melodična linija soprana, ki se vzpne $\checkmark$ ambitusu sekste in vkijučuje poleg postopnega gibanja tudi terčni in kvartni skok, tisto, kar že takoj na začetku najočitneje razlikuje prvi stavek Lassovega moteta od ustreznega pasusa Gallusove, Ingegnerijeve in Viadanine skladbe. Sicer pa je ta stavek tudi pri Lassu v bistvu homofonske strukture, le da učinkuje njegova homofonija manj kompaktno, ker so posamezni glasovi že vse od tretjega takta dalje ritmično diferencirani (Pr. 10).

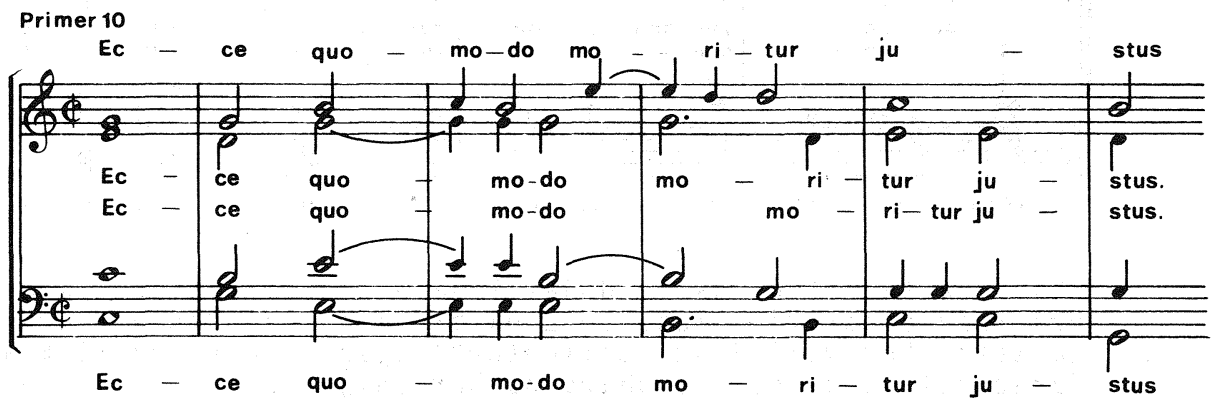

Začetek drugega stavka (Pr. 11) uvaja imitacijski postop med tenorjem in cantusom. Zdaj se melodična linija slednjega še bolj razpne, skladatelj pa je dosegel razredčitev zvočnega

5 W. Boetticher, Orlando di Lasso und seine Zeit, Kassel 1958, 658. Lassov "Ecce quomodo moritur justus" hrani Bavarska drzavna biblioteka $v$ kodeksu 2749, $v$ katerega je vključen poseben fascikel z naslovom "Responsoria 4 voci, pro Triduo Sacro in Nocturno II et III." Na koncu tega stoji tudi datum 28.III.1582, ki ga je pripisal kopist.

6 Liber usualis, Toumai 1964, 767-768.

7 R. Stevenson, Spanish Cathedral Music, Berkeley-Los Angeles 1961, 454 ss.

8 G. Watkins, Gesualdo - The Man and His Music, London 1976, 105-110. 

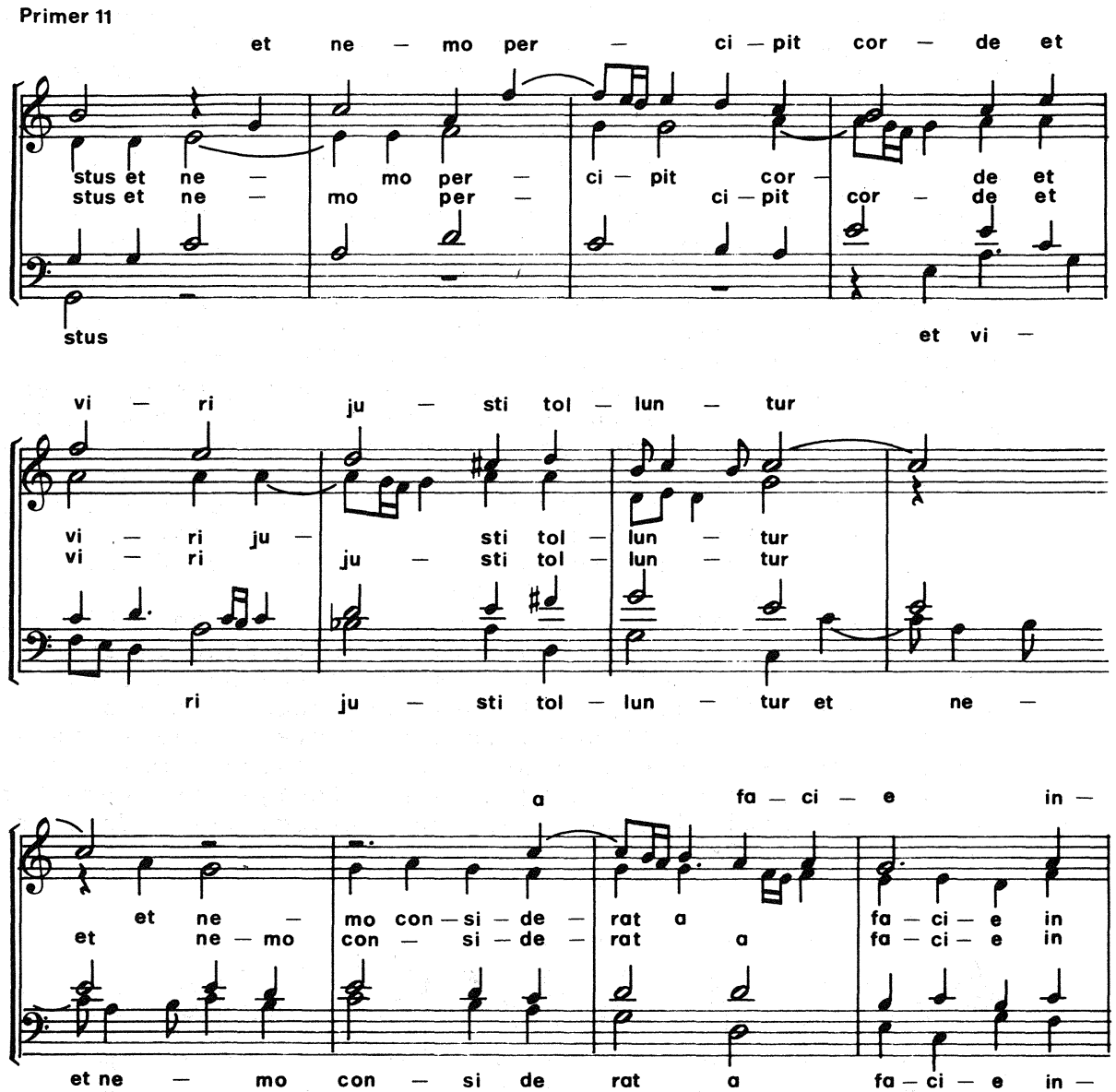

tkiva na ta način, da je dodelil basu daljši premor. Ta se pridružuje ostalim glasovom z ekspresivno melodično frazo šele na tekst "et viri justi tolluntur", kjer podpira proti kraju izraznost še kromatsko obarvana harmonija (sosledje akordov g-mol, A-D-G-dur). Po zasnovi je prejšnjemu podoben tretji stavek. Tudi tu je značilna na začetku razredčitev zvočnega tkiva, le da je tokrat premor $v$ sopranu, na koncu pa harmonska okrepitev, ki je izvedena $z$ avtentično kadenco na toniki dorske tonalitete (zveza akordov A-D-dur, gl. pr. 12).

Polifonsko je zasnovan tudi štiriglasni in nekoliko bolj trpko zveneči "Ecce, quomodo moritur justus" T. L. de Victoria iz njegove zbirke "Officium Hebdomadae Sanctae", ki je izšla leta 1585 v Rimu.7 Seveda pa je v uglasbitvi španskega mojstra linearni princip dosti bolj izrazit zaradi stalne uporabe imitacije. Ta skladba je s svojim umirjenim melodičnim tokom tel skladnim medsebojnim prepletanjem in dopolnjevanjem linij lep primer rimskega stila. V njej ni mesta za močnejše kontraste in tako se tudi psalmov verz (c) po fakturi in izrazu, navzlic 


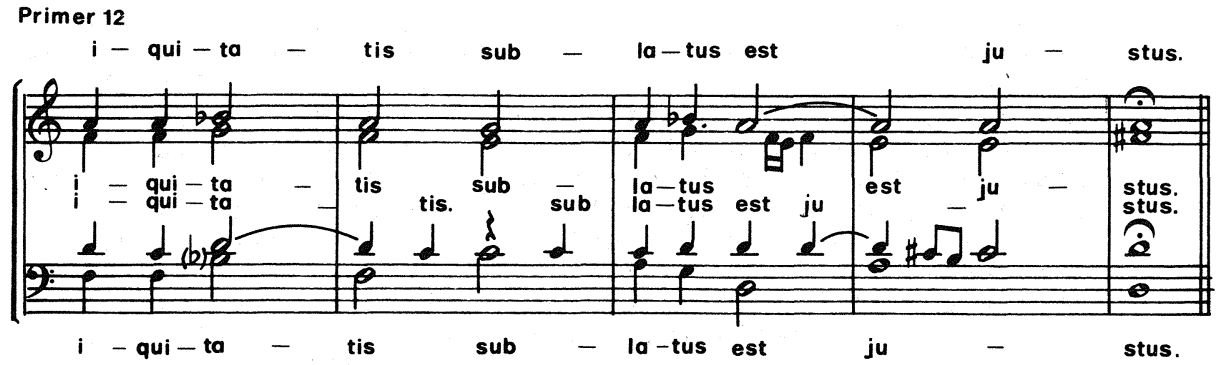

zmanjšanemu številu glasov na tri, pravzaprav ne razlikuje od ostalih delov. Iz homogene celote nekoliko izstopata le imitacijski začetek z dolgimi notnimi vrednostmi in refren, katerega besede "Et erit in pace" je skladatelj odel $v$ masivno akordiko (Pr. 13, 14).

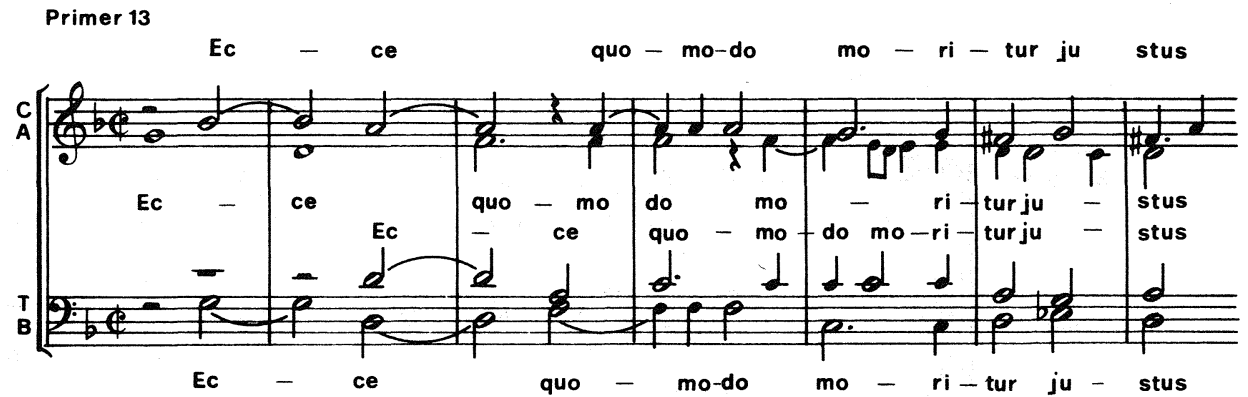

Primer 14

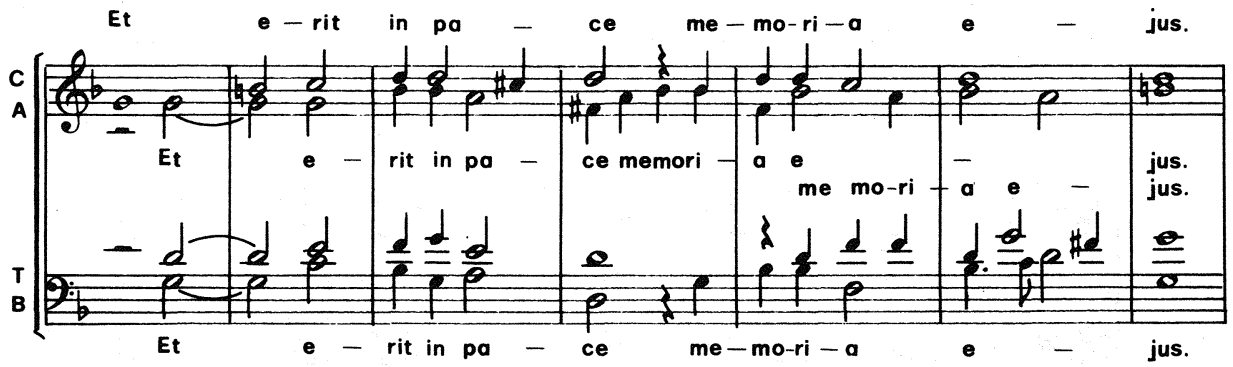

Nekaj povsem svojstvenega je "Ecce, quomodo moritur justus" deset let mlajšega Gallusovega sodobnika Carla Gesualda da Venosa iz njegove zbirke "Responsoria et alia ad officium hebdomadae sanctae spectantio sex vocibus" (Gesualdo 1611). Ta uglasbitev pravzaprav več ne sodi v območje tako imenovane klasične vokalne polifonije 16. stoletja, ampak že kaže značilnosti manierizma, stilne smeri, ki je odigrala pomembno vlogo med renesanso in barokom. 8 Tako je tudi za Gesualdov "Ecce, 
quomodo moritur justus" bolj ali manj značilno fragmentiranje fakture in pojavljanje ostrih kontrastnih elementov vozkem prostoru. Tu je vseskozi prisotna razdiralnost Gesualdovega manierističnega načina izražanja, ki je odraz močne reakcije nasproti konstantnemu toku polifonije ars perfecta in se poslužuje kromatike in harmonskega presenečanja. Da pri tem skladatelj ne more pogrešati "prepovedanih" melodičnih intervalov, harmonskih prečij, kromatičnih terčnih zvez, menjavanja tonalitetne ravni oziroma tonalitetne ambivalence, je povsem razumljivo. Tako srečujemo harmonske postope, ki jih je enako težko razložiti z vidika modalnega sistema kot kasnejše funkcionalne harmonije. Za razliko od Gallusa in nekaterih drugih njegovih sodobnikov Gesualdov "Ecce, quomodo moritur justus" več ne označujeta zadržanost in plemenita preprostost, ampak močan afekt in dramatska vznemirjenost, kar še zlasti velja za prvi del. (a). čeprav je tu podobno kot pri Gallusu, Ingegneriju in Viadani začetek akordsko deklamativen, je harmonsko bolj izrazit in napet: svetlim akordom C-dura sledita kromatska modulacijska odmika $v$ A- in D-dur, ki sta vsakikrat izvedena z zmanjšanim sekstakordom (Pr. 15). Seveda ima tudi

Primer 15
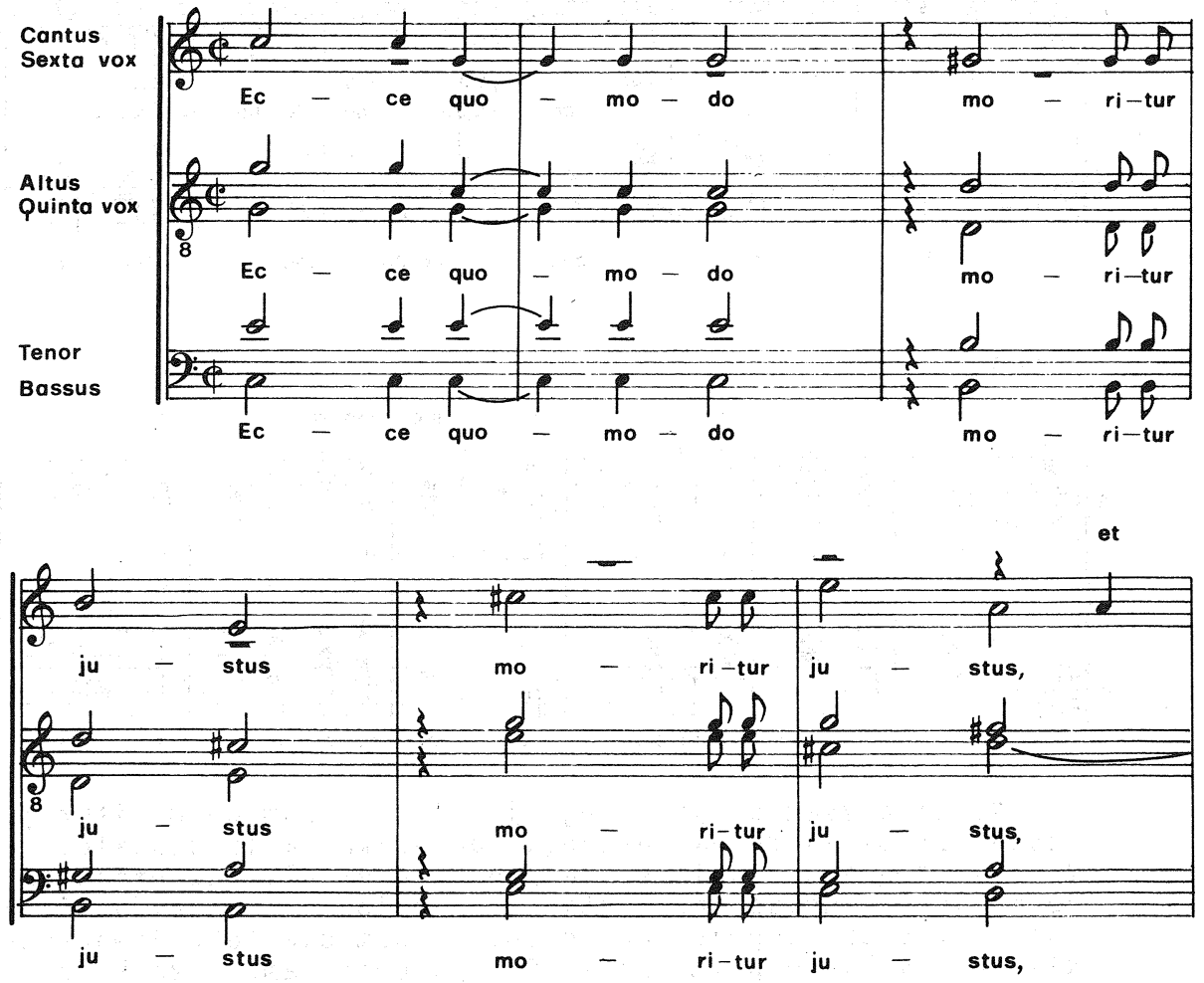
svojo težo ponovitev besedi "moritur justus", kjer gre ne glede na zamenjavo vloge quintusa in tenorja ter nastop sextusa ob premoru soprana pravzaprav za prestavitev celotnega zvočnega gradiva za kvarto navzgor. Zatem se zvočno tkivo polifonsko razprede, poudarek pa dobi beseda "percipit", zaznamovana s kratkim tritonskim motivom, ki se ponavlja in je voden skozi glasove (Pr. 16). V tej zvezi še ne pozabimo na vlogo disonance,
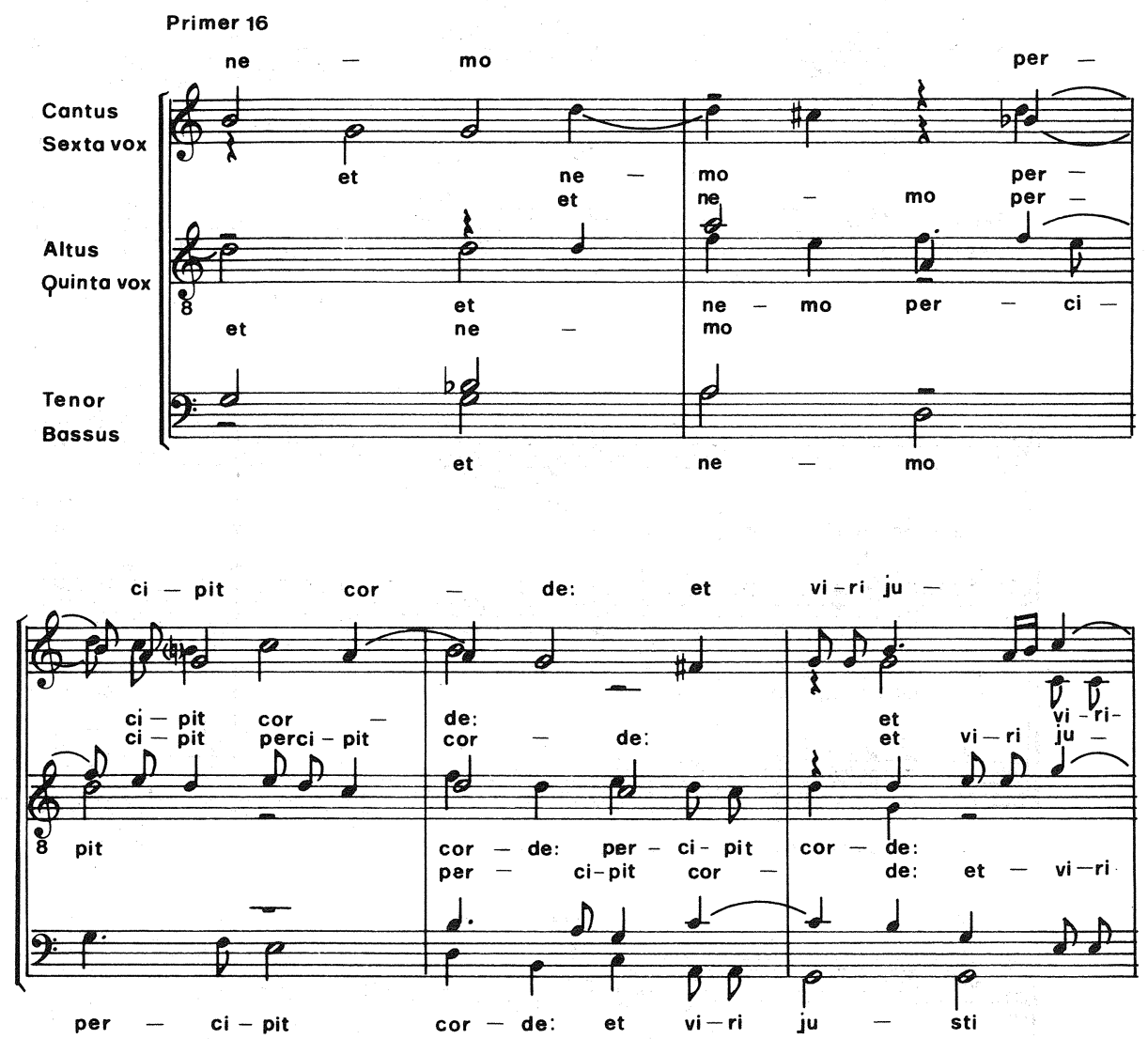

septimni zadržek med altom in basom. Ta se sicer regularno razveže navzdol, vendar njegov razvez prehodno disoniras sosednjim nižjim glasom (Pr.17). Nadaljevanje, kjer je zlasti zaznavna fragmentarnost fakture, je vsekakor zelo dramatično in predstavlja tudi močan izrazni vrh celotne kompozicije, V ozko odmerjenem prostoru le dveh taktov vnese nenavaden nemir v zvočno dogajanje koncizen, ritmično priostren motiv na "tolluntur", ki doživlja pri prehajanju iz glasu v glas različne spremembe. Sledeči homofonski člen učinkuje predvsem z zvočnostjo nekaterih apartnih akordskih zaporedij, kot so: d-mol-H-dur, e-mol-E-dur, G-E6 $\frac{5}{6}-A d u r, p r i$ čemer túdi ne prezrimo

$9 \quad$ G. Watkins, ibdo, 284.

10 Celotna izdaja Gesualdovih kompozicij je izšla šele v letih 1959-1966. 

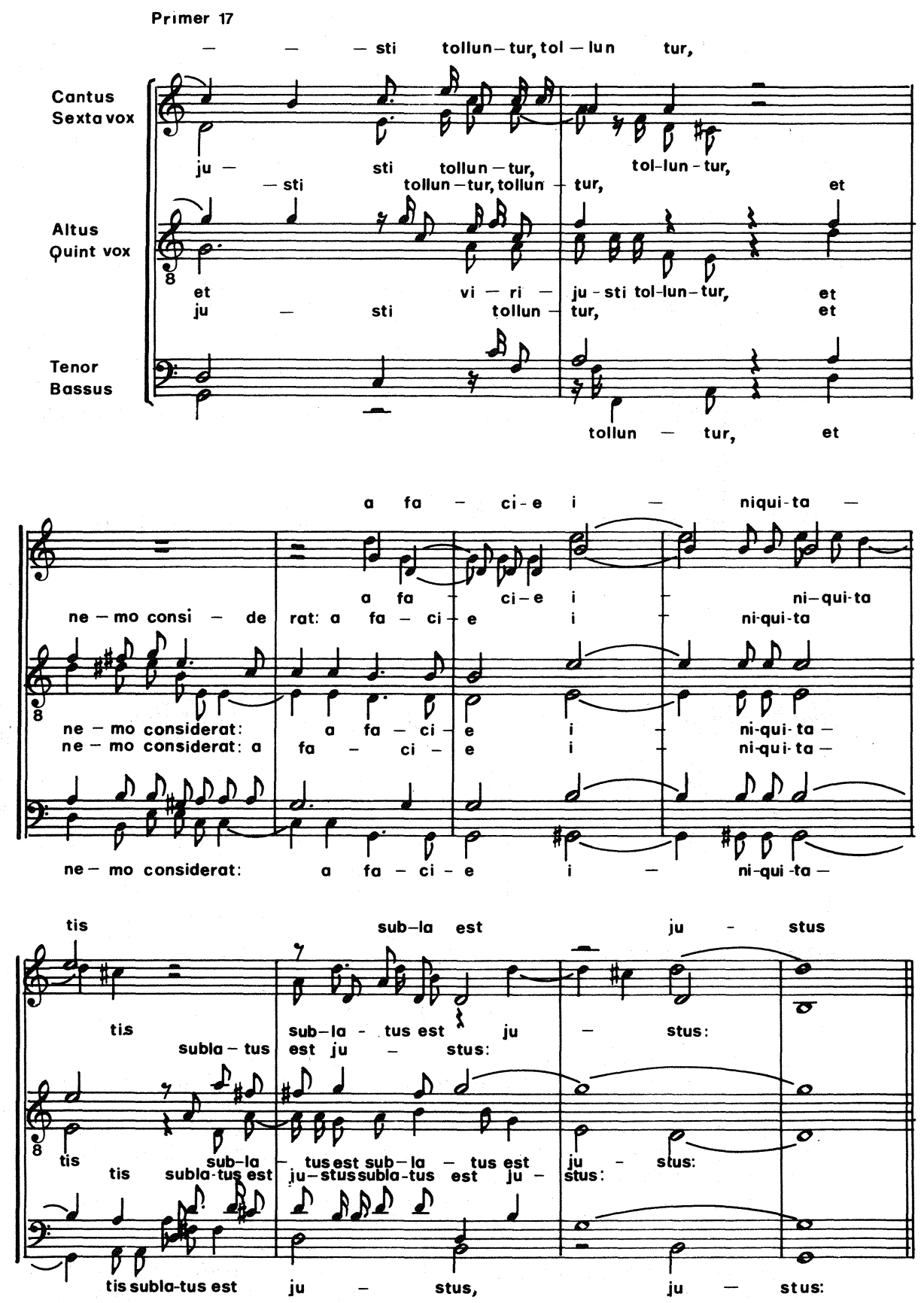
izstopajočega melodičnega vodenja soprana in alta, ki napravita istočasno intervalski skok velike sekste navzgor. Medtem ko zaključne takte uvaja kopičenje imitacijskih vstopov s kratko, a vendar karakteristično temo, nas na samem koncu še preseneti razvez zmanjšanega sekstakorda e-g-cis $v$ G-dur, saj bi glede na njemu lastno tendenco pričakovali razvez v D-dur。 Z začetkom refrena (B), ki predstavlja tudi tonalitetno (E-dur) izrazit kontrast, se dramatska vzburjenost pomiri. Skoro docela homofonski refren je najkrajši in najbolj kompakten del kompozicije, saj je v njem stalno prisotnih vseh šest glasov. Hkrati je tudi edini del, ki kaže tonalitetno zaokroženost: ista tonaliteta (E-dur) na začetku in koncu. V psalmovem verzu (c), ki je le štiriglasen, je torej Gesualdo podobno kot Ingegneri ali de Victoria zmanjšal število glasov in tako začasno izključil sodelovanje sextusa inquintusa. Za razliko od obeh sodobnikov pa je imitacijsko uglasbil le drugo polovico psalmovega verza. Seveda tudi tu ne manjka izrazito modernih potez in prekršitev pravil klasične vokalne polifonije 16. stoletja: kar na štirih mestih odkrijemo prečje, še očitnejša pa je uporaba zmanjšane kvarte v temi na besedi "de angustia" (Pr. 18). Nedvomno je

Primer 18

de an-gu-sti - a, et de ju-di - ci-o sub-la - tus est, et de ju-di-

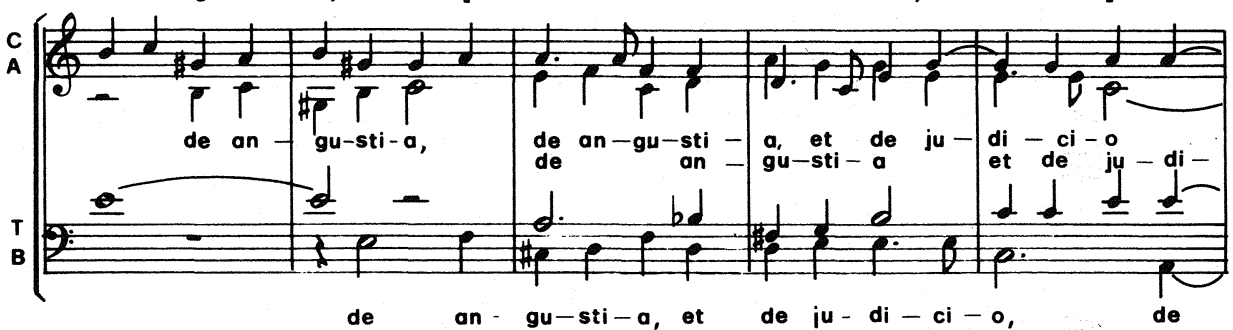

imel Gesualdo globoko utemeljen vzrok, da svoje kompozicije ni zaključil kot navadno drugi sodobniki z refrenom (B), ampak da je temu dodal še ponovitev dramatičnega prvega dela (a), saj je s tem dosegel izrazno najprepričljivejši konec in oblikovno najpopolnejšo zaokrožitev celote. Gesualdov "Ecce, quomodo moritur justus" je podobno kot vrsta drugih njegovih responsorijev glasbena umetnina polna tistega žara, kot ga cerkvena kompozicija dotlej skoroda ni poznala. Tu sta zajeta, kot pravi Glenn Watkins, patos in tragedija, ki nam odmevata iz liturgičnega besedila s takšno silo občutenja, kot še nikdar poprej. 9

ceprav smo se $v$ našem razpravljanju srečevali le $s$ kompozicijami umetniške vrednosti, se nam po izvedeni analizi in primerjavi motetov "Ecce, quomodo moritur justus", $k i$ so jih napisali Gallus in nekateri njegovi sodobniki, ni težko odločiti, da postavimo glede tehtnosti skupaj na prvo mesto kompoziciji J. Gallusa in C. Gesualda da Venosa kot eminentna dosežka dveh velikih mojstrov svojega časa. V obeh primerih je čutiti močno osebno prizadetost avtorja in veliko izpovedno moč, ki nas globoko prevzame in pretrese. Seveda je to doseženo vsakikrat s povsem drugačnimi izraznimi sredstvi in tako sta si kompoziciji po svojem značaju naravnost nasprotni. Gesualdova je emocionalno razgreta, nemirna, dramatsko vzburjena 
in razcepljena, hkrati pa je tudi bolj zapletena in umetelna $v$ gradnji ter bogatejša vizraznih sredstvih. Tako je v svoji izpovedi manj neposredna, toda zahtevnejša za izvajalca kot poslušalca. Medtem ko je slava Gesualda da Venosa temeljila le na madrigalih, je ostal njegov religiozni opus, v katerem zavzemajo posebno važno mesto prav responsoriji, do nedavnega skoro docela neznan. 10 Navzlic osebni prizadetosti avtorja pa označuje Gallusov "Ecce, quomodo moritur justus" klasična umirjenost in hkrati neka stoičnost. Tu se združuje preprosta, logična in vseskozi napeta gradnja s presenetljivo intenziteto ekspresivnosti in globino izpovedi. Gallusova kompozicija je res vzoren primer tiste izredne umetnosti, ki doseže maksimum izraza z minimalnimi sredstvi. Tako je tudi vse bolj jasno, zakaj je med moteti "Ecce quomodo moritur justus" prav Gallusov tisti, ki je že stoletja deležen nezmanjšane slave. To je umetnina, $k i$ je enako pri srcu glasbenemu strokovnjaku kot ljubitelju. Ob Gallusovem motetu deluje istoimenski in po strukturi sorodni motet $M$. A. Ingegnerija, ki pa je otožnejši, mehkejši in temnejši, skoraj bledo. še bolj velja to seveda za Viadanino uglasbitev. Lassov "Ecce, quomodo moritur justus", ki ga označuje objektivnost in svetlost izraza, kakor tudi tisti nekoliko trpkejši de Victorie pa sta ob prevladujoči polifonski gradnji po značaju že tako različna od Gallusovega, da tu ocenjevanje s skupnega gledišča spet ni mogoče.

Ker spada responsorij "Ecce, quomodo moritur justus" med splošno razširjene obredne speve velikega tedna, je razumljivo, da ga je v Gallusovem času komponiralo poleg že obravnavanih, še več skladateljev. Kot ugotavlja G. Watkins, so v 16. in 17. stoletju uglasbili v Italiji ciklus responsorijev za veliki teden tudi Bernardo Pisano (1520), Paolo Ferrarese (1565), Vincenzo Ruffo (1586), Pandolfo Zallamella (1590), Camilio Lombardi (1592), Mauro Panormitano (1599), Pompio Nenna (1607) in Marco da Gagliano (1630). 11 Glede na podatke, ki nam jih nudita Repértoire International de Sources Musicales in Eitnerjev Biographisches-Bibliographisches Quellen-Lexikon, pa cikli žal sploh niso ali pa so le pomanjkljivo ohranjeni, tako da bi tu za natančnejše preučevanje prišla v poštev le Lombardi in Nenna. Seveda so morali ustvarjati cikle responsorijev za veliki teden še skladatelji drugih narodnosti, jn če že ne $v$ celoti,vsaj posamezne speve kot npr. J. Gallus.12 Nadaljnje iskanje v tej smeri bi lahko odkrilo še druge uglasbitve istega teksta, 13 kar bi utegnilo tudi dopolniti stilnokritično osvetlitev znamenite Gallusove skladbe.

\section{SUMMARY}

In the comparative study presented here the author first concentrates on "Ecce, quomodo moritur iustus" by the composers M. A. Ingegneri and L. Viadana and on Gallus' motet with the

$v$ Hamburgu in sta jo pripravila W. Weismann in G. E. Watkins. Obsega deset zvezkov, od teh vsebuje sedmi "Responsoria et alia ad Officium Hebdomadae Sanctae Spectantiae"。

G. Watkins, ibd., 261-262. 
same text; the compositions have clearly features in common compact homophony, sylzabic and declamatory melody, clear articulation and formal disposition with refrain ( $a B a B$ ). Especiall interesting is Ingegneri's composition, with its melody within the first six measures being nearly identic with that by Gallus. It appears that the two composers set to music this text at almost the same, or even at the same time - but each independently of the other. Although the degree of relatedness between Gallus' and Viadina's "Ecce, quomodo moritur iustus" is smaller than that between the corresponding compositions by Gallus and Ingegneri, here there can be found also some similarities concerning detailed points.

Very different from the above mentioned motets "Ecce, quomodo moritus iustus" are in character and structure motets bearing the same title and composed by o. di Lasso, T. I. de Victoria, and $C$. Gesualdo da Venosa. Lasso's and Victoria's motets are written poliphonically, but the composition by the spanish master assumes through the constant use of imitation a rather more pronounced linear aspect. Something wholly specific is "Ecce, quomodo moritur iustus" by C. Gesualdo da Venosa, which distinctly shows already signs of mannerism and which is characterized by fragmentation of texture and the use of sharply contrasting elements within the narrow space. That in this context emerge. "forbidden" melodic intervals, cross-relations, chromatic third-relations and changes of tonality levels is perfectly understandable.

Although our discussion here relates to compositions of artistic values, it is not difficult to decide to put first the compositions by J. Gallus and $C$. Gesualdo da Venosa as two eminent achievements of two great masters of their time. In both cases we feel the author's strong personal affection and powerful expression which are deeply moving. This is of course achieved by perfectly different means of expression and so the two compositions are very contrary to each other. Gesualdo's is emotionally fervent, restless, dramatically agitated and split up, but at the same time more complex and artistic in structure as well as richer in means of expression. As such it is in its message less direct and both for the performer and the listener more demanding. In spite of the personal commitment of the author, Gallus' "Ecce, quomodo moritur" is marked by classical serenity and at the same time by a kind of stoicism. Here the straightforward, logical and throughout tense structure is combined with a surprising intensity of expressiveness and a deep intrinsic meaning.

12 Njegova druga knjiga "Opus musicum" vsebuje v prvem razdelku "De Passione Domini nostri Jesu Christi" še tele posamezne responsorije za matutine velikega tedna: "O vos ommes, qui transitis per viam" (dve razliěni uglasbitvi), "Sepulto Domino signatum est monumentum", "Recessit pastor noster"。

13 Doslej mi je poleg obravnavanih motetov znan le še "Ecce, quomodo moritur justus" salzburškega skladatelja Andreasa Hoferja, ki pa je deloval ze kasneje, $v$ drugi polovici 17. stoletja. Hoferjev motet je objavil $S$. Lïck $v$ zbirki Compositionen für die Kirche, V. Prim. še F.j. Fétis, Biographie universelle des musiciens, IV, Paris 1874, 343. 